\title{
Three-dimensional printed hydroxyapatite bone tissue engineering scaffold with antibacterial and osteogenic ability
}

\author{
Liu Zhongxing ${ }^{1+}$, Wu Shaohong ${ }^{2 \dagger}$, Li Jinlong ${ }^{1 *}$, Zhang Limin ${ }^{3}$, Wang Yuanzheng ${ }^{1}$, Gao Haipeng ${ }^{1}$ and Cao Jian ${ }^{1 *}$
}

\begin{abstract}
The development of an effective scaffold for bone defect repair is an urgent clinical need. However, it is challenging to design a scaffold with efficient osteoinduction and antimicrobial activity for regeneration of bone defect. In this study, we successfully prepared a hydroxyapatite (HA) porous scaffold with a surface-specific binding of peptides during osteoinduction and antimicrobial activity using a three-dimensional (3D) printing technology. The HA binding domain (HABD) was introduced to the C-terminal of bone morphogenetic protein 2 mimetic peptide (BMP2-MP) and antimicrobial peptide of PSI10. The binding capability results showed that BMP2-MP and PSI10-containing HABD were firmly bound to the surface of HA scaffolds. After BMP2-MP and PSI10 were bound to the scaffold surface, no negative effect was observed on cell proliferation and adhesion. The gene expression and protein translation levels of type I collagen (COL-I), osteocalcin (OCN) and Runx2 have been significantly improved in the BMP2-MP/HABP group. The level of alkaline phosphatase significantly increased in the BMP2-MP/HABP group. The inhibition zone test against Staphylococcus aureus and Escherichia coli BL21 prove that the PS110/HABP@HA scaffold has strong antibacterial ability than another group. These findings suggest that 3D-printed HA scaffolds with efficient osteoinduction and antimicrobial activity represent a promising biomaterial for bone defect reconstruction.
\end{abstract}

Keywords: Bone scaffold, 3D printed, Hydroxyapatite, Osteoinduction, Antibacterial

\section{Introduction}

Bone defect requires surgical repair to regenerate its function. The defect site requires scaffold to induce migration, ingrowth and osteogenic differentiation of surrounding cells. Scaffold materials must have good mechanical properties and cellular compatibility, orderly porous structure and osteoinduction capability. The most commonly used materials for the repair of bone defect include allografts, xenografts, metals [1], inorganic materials [2] and polymer materials [3].

\footnotetext{
* Correspondence: cflijinlong@163.com; caojian2005088@sina.cn

${ }^{\dagger}$ Liu Zhongxing and Wu Shaohong contributed equally to this work.

${ }^{1}$ Department of Orthopedics, Affiliated Hospital of Chifeng University, Inner Mongolia 024000 Chifeng, People's Republic of China

Full list of author information is available at the end of the article
}

Allografts and xenografts are the most commonly used bone repair materials for bone repair in early clinical practice [4]. Although the immune rejection of allografts is low, there are still some shortcomings, such as the limited source of grafts and the risk of infection in the donor part [5]. Although the source of xenograft bone is extensive, it also has the risk of immune rejection [6]. Both methods will be phased out with the development and application of new synthetic materials.

Synthetic polymer materials have made great progress in the field of bone defect repair due to its advantages of extensive artificial synthesis, good mechanical properties, the use of biodegradable polymers and great potential for surface modification. Dinghua Liu et al. used threedimensional (3D) printing technology to prepare a 
polycarbonate (PCL) porous scaffold containing strontium-containing hydroxyapatite (HA), which effectively promoted osteogenic differentiation and bone defect repair [7]. Polymer materials generally lack biological activity. Thus, they need to be combined with other biologically active materials or surface-modified to meet the requirements of bone defect repair. Lei Chen et al. bound BMP-2 and ponericin G1 onto the surface of PLGA scaffolds via poly(dopamine). This kind of surface modification of PLGA scaffolds enhanced its osteoinduction and antimicrobial activity [8]. Xiaoyuan $\mathrm{Li}$ et al. bound gelatin/nanohydroxyapatite and antimicrobial peptide onto the surface of PLA scaffolds, and this surface modification method enhanced the cellular adhesion, calcium deposition and antimicrobial ability of PLA scaffolds [9].

Inorganic materials, such as HA, $\beta$-tricalcium phosphate and calcium-phosphate cement, have been widely used in bone defect repair scaffolds due to their biocompatibility and osteoconductive features $[2,10]$. However, the osteogenesis capability of these materials is often insufficient and several additives (such as growth factors [11], trace elements [12, 13], stem cells [14], etc.) need to be added to accelerate osteogenic induction. Bone morphogenetic protein 2 (BMP2) has been widely used in bone repair scaffolds as a growth factor that can promote osteogenesis. The combination of BMP2 and biomaterials mainly includes blending $[11,15,16]$, covalent bonding [17, 18] and specific binding [19]. Daixu Wei et al. used Soybean lecithin (SL) to encapsulate BMP2 and then prepared microspheres and scaffolds using the oil-in-water emulsion-solvent evaporative method and modified solid-liquid phase separation method. These microspheres and scaffolds showed strong abilities of stem cell attachment and proliferation, matrix mineralization abilities $[15,16]$. Bing Chen et al. used genetic engineering recombination technology to introduce von Willebrand polypeptide into BMP2; this polypeptide can bind BMP2 onto the surface of collagen material and improve the utilisation rate of BMP2, thus accelerating the osteogenesis capability of scaffold [19]. Various kinds of growth factors have been applied with special binding technology to enhance their binding capability on the material surface and obtain good tissue repair effect. Ito, Yoshihiro et al. introduced 3,4dihydroxyphenylalanine (DOPA) molecule at the end of insulin-like growth factor 1 (IGF1); the adhesion efficiency of DOPA-IGF1 on the Ti surface was enhanced due to the adhesion capability of DOPA [20]. To find a specific binding peptide with HA, Matthew L. Becker et al. used phage display technology to identify a peptide sequence that exhibits high specificity binding to HA [21]. The sequence of this polypeptide is SVSVGMKPSP $\mathrm{RP}$ and was named HABP. The above studies have proven that when growth factors are modified with binding peptides, their stability on the material surface can be significantly enhanced, thus enhancing their own biological function.

In this study, we used HA binding domain (HABD) to enhance the binding capability of BMP2 mimetic peptide (BMP2-MP) and PSI10 with HA to increase the osteoinduction and antibacterial capability of 3D-printed HA scaffolds. BMP2-MP (KIPKACCVPTELSAISMLYL) can promote osteogenesis-related gene expression, production of extracellular matrix and osteogenetic differentiation [22]. An antimicrobial peptide PSI10 (RRWPWW PWRR) was designed according to the research shows strong bactericidal activity. The minor inhibitory concentration (MIC) of PSI10 against to Escherichia coli (E.coli), Salmonella typhimurium, Bacillus subtilis, Staphylococcus aureus are 2, 4, 2 and $2 \mu \mathrm{g} / \mathrm{ml}$, respectively. PSI10 also had a good antibacterial effect on methicillin-resistant Staphylococcus aureus (MRSA) and vancomycin-resistant Enterococcus faecium (VRE) [23]. Given the advantages of the cooperative effect of HABD with BMP2-MP and PSI10, HABD can enhance the osteoinduction and antibacterial capability of 3D-printed HA bone defect scaffolds. The osteoinduction and antibacterial activity of HA scaffolds had been intensively studied and evaluated in vitro.

\section{Materials and methods}

Commercially pure HA (average diameter $<200 \mathrm{~nm}$ ) were purchased from MACKLIN Co., Ltd. BMP2-MP, BMP2-MP/HABP, PSI10, PSI10/HABP and their corresponding fluorescein isothiocyanate (FITC)-labelled polypeptides were synthesised by Sangon Biotech Co., Ltd. Pluronic F-127 was purchased from Sigma.

\section{Manufacture of 3D-printed bone defect scaffolds}

The geometry of the scaffold $(\Phi 8 \mathrm{~mm} \times \mathrm{H} 3 \mathrm{~mm})$ was designed by 3DMAX 2017 software and exported in STL format. Then, the STL file was imported into Simplify3D software for print parameter setting. The filling rate was set at $50 \%$, the printing speed was set at $6 \mathrm{~mm} / \mathrm{s}$ and the filament angles from layer to layer were set at $0^{\circ}, 45^{\circ}, 90^{\circ}$ and $135^{\circ}$. The printing ink was a mixture of HA and Pluronic F-127 aqueous solution $(20 \mathrm{wt} \%)$ at a $50 \%: 50 \%(\mathrm{~W} / \mathrm{V})$ ratio. The printing ink was stirred vigorously for $15 \mathrm{~min}$ and then filled into a $2.5 \mathrm{ml}$ syringe. The inner diameter of the printer head was $0.4 \mathrm{~mm}$. The biological 3D printer (3D-BioART, UB biotech. Co., Ltd) was used for scaffold printing. Finally, all scaffolds were dried overnight and sintered at $1100{ }^{\circ} \mathrm{C}$ for $3 \mathrm{~h}$ using a muffle furnace (Blue M LGOTM, Thermo). 


\section{Characterisation of 3D-printed scaffolds}

Micro-computed tomography (micro-CT) (SKYSCAN 1275) was used to scan and reconstruct the scaffold. Then, the porosity and pore properties of the scaffold were calculated and observed based on the reconstruction data. The microstructures and surface topography of the scaffolds were observed by optical microscopy (Olympus IX71) and scanning electron microscopy (SEM, Merlin Compact; Zeiss, Germany) in 100×, $1 \mathrm{~K} \times$ and $10 \mathrm{~K} \times$ magnification. The phase compositions of HA scaffolds were analysed by X-ray diffraction (XRD). The compression strength of the HA scaffold before and after sintering was tested by universal mechanics testing machine (Instron 3400).

\section{Fabrication of BMP2-MP/HABP and PSI10/HABP-modified scaffolds}

BMP2-MP/HABP (500 ng/mL), BMP2-MP (500 ng/mL), PSI10/HABP $(100 \mu \mathrm{g} / \mathrm{mL})$ and PSI10 $(100 \mu \mathrm{g} / \mathrm{mL})$ solutions were dissolved in phosphate-buffered saline (PBS). The HA scaffolds were immersed in $1 \mathrm{ml}$ different solutions for up to $12 \mathrm{~h}$ at $4{ }^{\circ} \mathrm{C}$ with shaking (60 rpm) to enable the homogeneous dispersion of polypeptides. These surface-modified scaffolds were rinsed thrice with PBS to remove unbound polypeptides. SEM was used to evaluate the surface morphology of the scaffolds after their incubation with different polypeptides.

\section{Absorption and release capability of BMP2-MP/HABP and PSI10/HABP with HA scaffolds}

To measure the absorption and release capability of BMP2-MP/HABP and PSI10/HABP with HA scaffolds, we incubated $1 \mathrm{ml}$ FITC-labelled polypeptides with the scaffolds for $12 \mathrm{~h}$ at $4{ }^{\circ} \mathrm{C}$ with shaking $(60 \mathrm{rpm})$. Then, the scaffolds were washed thrice with PBS. All fluorescence images of scaffolds were captured by a fluorescence imaging device (CRI Maestro). The average signal data of every scaffold were calculated for statistical analysis $(n=3)$. In order to calculate the amount of polypeptide absorption and release, we measured and calculated the standard curve of polypeptide concentration and fluorescence intensity (Fig. S1). After the HA scaffold was soaked in the polypeptide solution, the fluorescence intensity of the remaining polypeptide solution was measured using a plate reader (Tecan M200), and the amount of the remaining polypeptide was calculated according to the fluorescence intensity using the standard curve. The amount of scaffold absorptive polypeptides was the total amount of polypeptides minus the amount of remaining polypeptide. To detect the polypeptide releasing ability from the HA scaffold, scaffolds were immersed in $2 \mathrm{ml}$ PBS solution and incubated at $4{ }^{\circ} \mathrm{C}$ with shaking $(60 \mathrm{rpm}) .100 \mu \mathrm{l}$ of the release solution was taken at time points $1,3,6,12,24,48$ and $72 \mathrm{~h}$ for fluorescence detection, and the amount of polypeptide released was calculated according to the fluorescence intensity. The cumulative release rate was calculated as following formula: the cumulative release rate $(\%)=$ the amount of cumulative release of polypeptides (time point) $\times 100 /$ total amount of polypeptide absorption.

\section{Antibacterial activity evaluation}

The inhibition zone test was used to evaluate the antimicrobial activity of different scaffolds. Staphylococcus aureus (S. aureus) and Escherichia coli BL21(E. coli) strains (bought from China Center of Industrial Culture Collection, China) were used in this test. Firstly, $100 \mu \mathrm{l}$ bacterial solution $\left(4.0 \times 10^{4}\right.$ bacteria/ml $)$ was spread onto the LB agar plate. Then, the scaffolds were placed onto the surface of the LB agar plate. After $12 \mathrm{~h}$ of incubation at $37^{\circ} \mathrm{C}$, inhibition zone size was calculated by the software ImageJ.

\section{Cell adhesion and proliferation assays}

MC-3T3-E1 cells were seeded onto different scaffolds to investigate the effect of BMP2-MP/HABP and PSI10/ HABP-coated scaffolds on cellular morphology and proliferation. MC-3T3-E1 cells were purchased from the Chinese Academy of Sciences Shanghai Cell Bank and cultured in high-glucose Dulbecco's Modified Eagle Medium (DMEM) supplemented with $10 \%$ foetal bovine serum. The culture conditions were $37{ }^{\circ} \mathrm{C}$ in a humidified atmosphere containing $5 \% \mathrm{CO}_{2}$ and the medium was renewed every two days. Cell proliferation on different scaffolds were determined using the Cell Counting Kit-8 (CCK-8, Dojindo, Japan) assay. Firstly, the scaffolds were sterilised by immersion in $75 \%$ alcohol for $30 \mathrm{~min}$ before coating with different polypeptides. The polypeptides were sterilised by filtration using $0.22 \mu \mathrm{m}$ filter membrane (Millipore). Then, MC-3T3-E1 cells were seeded on different scaffolds at the density of $\left(5 \times 10^{4}\right.$ cells $/ \mathrm{mL}$ ). After 3 days of culture, the medium was replaced by CCK- 8 . After $3 \mathrm{~h}$ of incubation, the absorbance values at $450 \mathrm{~nm}$ were measured on a multifunctional microplate scanner (Tecan Infinite M200). To investigate the cell adhesion and spreading capability on the different scaffolds, we incubated the cells with $2 \mu \mathrm{M}$ calcein AM (Beyotime) and $1 \mu \mathrm{g} / \mathrm{ml}$ propidium iodide (PI) for $30 \mathrm{~min}$ and rinsed them repeatedly with PBS. Finally, the cell/scaffold samples were observed under a fluorescence microscope (DM2500, Leica).

\section{Real-time quantitative polymerase chain reaction (qPCR)} analysis

MC-3T3-E1 cell suspension was seeded on different scaffolds at the density of $1 \times 10^{5}$ cells $/ \mathrm{mL}$ and continually cultured for 7 days. The total RNA was extracted 
using TRIzol reagent (Sigma) following the manual. RNA concentration was measured using NanoDrop 8000 (Thermo) and diluted with RNase-free water (Solarbio) to a final concentration of $200 \mathrm{ng} / \mu \mathrm{l}$. cDNA was prepared by reverse transcription of mRNA using the PrimeScript ${ }^{\mathrm{tm}}$ Kit (TAKARA). TB Green ${ }^{\circ}$ Fast $q$ PCR Mix (TAKARA) was used to evaluate the expression of osteogenic genes by $q \mathrm{PCR}$. The reaction conditions were: $95{ }^{\circ} \mathrm{C}$ for $30 \mathrm{~s}$ for 1 cycle and $95{ }^{\circ} \mathrm{C}$ for $5 \mathrm{~s}$ to $60{ }^{\circ} \mathrm{C}$ for $10 \mathrm{~s}$ for 40 cycles. Gene-specific primers, including glyceraldehyde-3-phosphate dehydrogenase (GAPDH), type I collagen (COL-I), osteocalcin (OCN) and Runx2, were designed using the primer design software Beacon 5.0 (Table 1). Each gene expression value was normalised to that of the housekeeping gene, GAPD $\mathrm{H}$. The results were reported as relative gene expressions. All experiments were performed in triplicate to obtain the average data.

\section{Western blot analysis}

The results of cell culture method were consistent with those of the qPCR method. The total proteins in each group were extracted using radioimmunoprecipitation assay lysis buffer (Beyotime). Protein concentration was determined using the $\mathrm{BCA}^{\mathrm{Tw}}$ Protein Assay Kit (PIERCE). Electrophoresis was performed using $12 \%$ sodium dodecyl sulfate polyacrylamide gel electrophoresis with $20 \mu \mathrm{g}$ protein per sample. The protein was transferred from the gel to the polyvinylidene fluoride (PVDF) membrane at $200 \mathrm{~mA}$ for $2 \mathrm{~h}$. The PVDF membrane was blocked with $5 \%$ skim milk for $2 \mathrm{~h}$, immersed in a primary antibody solution and incubated at $4{ }^{\circ} \mathrm{C}$ overnight. Next, the PVDF membrane was incubated with horseradish peroxidase-labelled secondary antibody at room temperature for $2 \mathrm{~h}$. The antibody dilution ratios were as follows: GAPDH: 1:2500 (ABCAM), Runx2: 1:2000 (ABCAM), COL-I: 1:2000 (ABCAM) and OCN: 1:2000 (ABCAM). The PVDF film emitted light under the reaction of an enhanced chemiluminescence substrate. X-ray film was used for exposure and photographing. The grey value of the blot was quantitatively calculated by ImageJ software [24, 25].

\section{Alkaline phosphatase (ALP) assay}

MC-3T3-E1 cells $\left(5 \times 10^{4} /\right.$ well $)$ were seeded onto scaffolds and cultured in high-glucose DMEM. After 7 days, the ALP activity of one group was assayed using a 5bromo-4-chloro-3-indolyl phosphate/nitro blue tetrazolium ALP colour development kit (Beyotime, China). ALP-positive cells were captured under a light microscope (Olympus IX71) in five randomly selected fields. Data are presented as mean \pm standard deviation (SD), with $n=3$. A cell lysate kit (Beyotime, China) was used in another group of cells to extract the total proteins in accordance with the specifications. ALP activity was assayed with a p-Nitrophenyl Phosphate (pNPP) Liquid Substrate System (Sigma) following the manufacturer's instructions. A total of $200 \mu \mathrm{l}$ pNPP solution was added to each well containing $10 \mu \mathrm{l}$ cell lysate. The plates were incubated at room temperature for $30 \mathrm{~min}$ and activities were detected and read at a wavelength of $405 \mathrm{~nm}$ (Thermo MK3). The protein concentration of cell lysates was quantified using the BCA Kit (Beyotime, China). ALP enzyme activity was calibrated using protein concentration.

\section{Statistical analysis}

All results were expressed as means $\pm \mathrm{SD}$. One-way analysis of variance with post hoc test was used to determine significant differences. $p<0.05$ was considered statistically significant difference and the data were indicated with (*) for probability less than $0.05(p<0.05)$.

\section{Results and discussion \\ Scaffold design and printing}

The 3D-printed HA scaffolds were prepared by a biological 3D printer (Fig. 1a). Images of each part of 3D printer see Fig. S2. The HA printing ink was extruded by $0.15 \mathrm{MPa}$ nitrogen to print out a computer-designed HA scaffold (Fig. 1b). The scaffold diameter decreased from $8 \mathrm{~mm}$ before sintering to $6 \mathrm{~mm}$ afterward mainly because F127 in the printing ink was burned up, causing the scaffold to shrink (Fig. 1c and d). The micro-CT scan showed a clear image of the HA scaffold, regular pore arrangement and connection. The porosity of HA scaffold before and after sintering was 27.45 and $26.53 \%$, respectively (Fig. 1d).

In this study, the filament angle between the scaffold layers was set to $45^{\circ}$ (Fig. 1e). Given this fibre orientation pattern, the scaffold was viewed from top to bottom and the pore pass-through area accounted for a small proportion of the area (Fig. 1f). This filling style was

Table 1 List of genes and primer nucleotide sequences

\begin{tabular}{lll}
\hline Gene annotation & Forward primer sequence & Reverse primer sequence \\
\hline RUNX2 & GCCCTCATCCTTCACTCCAAG & GGTCAGTCAGTGCCTTTCCTC \\
OCN & TCCAAGCAGGAGGGCAATAA & CAAGTCCCGGAGAGCAGCCA \\
COL-1 & CTGAAATGTCCCACCAGCC & GTCCGATGTTTCCAGTCTGC \\
GAPDH & AATGTGTCCGTCGTGGATCTG & CAACCTGGTCCTCAGTGTAGC \\
\hline
\end{tabular}



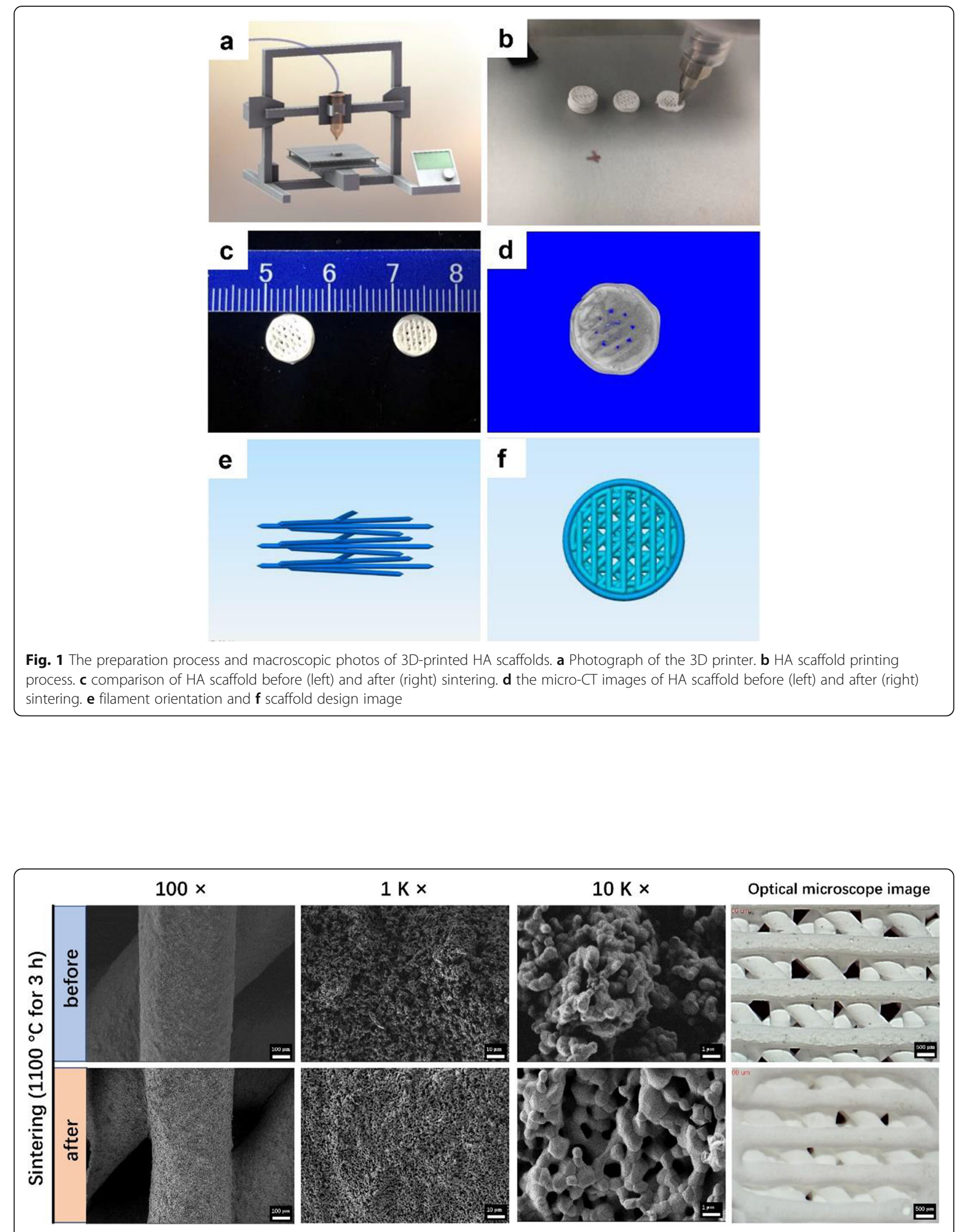

Fig. 2 Surface morphology and XRD analysis of 3D-printed HA scaffolds (before and after sintering) 
selected to allow the cells to thoroughly fill the interior of the scaffold and prevent them from rapidly flowing out of the pore. In many previous research, the commonly used filling angles of 3D printed scaffold was generally $45^{\circ}$ or $90^{\circ}$. Lei Chen et al. prepared a lithiumcalcium-silicate crystal bioscaffold for osteochondral interface reconstruction. The angle between the scaffold filaments was set at $90^{\circ}$ [26]. Wentao Dang et al. prepared a metal-organic framework nanosheet-structured scaffold for bone construction and tumour therapy. The angle between the scaffold filaments was $45^{\circ}$ [27]. Theoretically, the cell retention ability of $45^{\circ}$ would be better than that of $90^{\circ}$.

\section{Characterizations of HA scaffolds}

As shown in Fig. 2, the diameter of the filament before sintering was about $490 \pm 12.4 \mu \mathrm{m}$, whereas that after sintering was about $410 \pm 16.5 \mu \mathrm{m}$, indicating a shrinkage of $16.4 \%$, which was consistent with the macroscopic size shrinkage of the HA scaffold (Fig. 1c). The SEM images showed that the diameter of HA particles was between 200 and $500 \mathrm{~nm}$ before sintering and the micropores were relatively dense and irregularly arranged. After sintering, the diameter of HA particles was between 500 and $1.6 \mu \mathrm{m}$ and the micropores were relatively loose and arranged regularly. After sintering, the particles were closely connected and the crystals developed uniformly. The pore diameter of the scaffold was $584.5 \pm 12.3 \mu \mathrm{m}$ before sintering and $408.4 \pm 11.4 \mu \mathrm{m}$ after sintering, respectively. Figure 3 plots the XRD patterns of HA scaffolds before and after sintering. 'HA and glue mixed scaffold' and 'HA scaffold' represent the scaffolds without and with sintering at $1100{ }^{\circ} \mathrm{C}$ for $3 \mathrm{~h}$, respectively. All patterns were compared with the means of Joint Committee on Powder Diffraction Standards.
The HA scaffolds before and after sintering showed the same patterns with PDF (No. 09-0432). However, several redundant peaks appeared because of the incorporation of adhesive glue into HA powders before sintering (black arrows in Fig. 3).

The macro pore size and micro pore structure of scaffolds seriously affected the adhesion migration and osteogenic differentiation of cells around them. Tsuruga, E et al. showed that the optimal pore size for attachment, differentiation and growth of osteoblasts and vascularisation is approximately $300-400 \mu \mathrm{m}$ [28]. Jingjing Diaod et al. prepared calcium-phosphate scaffolds with different pore sizes $(100,250$ and $400 \mu \mathrm{m})$ and the results revealed that the scaffolds with pore structure of $100 \mu \mathrm{m}$ were the most efficient in inducing bone formation during the repair of flat bone defects. The scaffolds with a pore size of $400 \mu \mathrm{m}$ displayed the best capability for bone formation in the repair of long bone defects [29]. Therefore, when repairing bone defects in different positions, the pore size of the scaffold should be selected and designed in accordance with a specific condition, which will affect the repair efficiency. The pore size of the scaffold could be controlled by changing the size of the inner diameter of the printing head and the printing filling rate. The pore size of the scaffold prepared in this study is about $400 \mu \mathrm{m}$, so this scaffold is more suitable for repairing long bone defects.

\section{Absorption and release capability of BMP2-MP/HABP and PSI10/HABP with HA scaffolds}

We used a fluorescence imager to capture coloured photos when FITC-labelled polypeptides in different groups were incubated with HA scaffolds (Fig. 4a). The heat map of the image represents the amount of polypeptide on the scaffolds. The redder the picture, the more

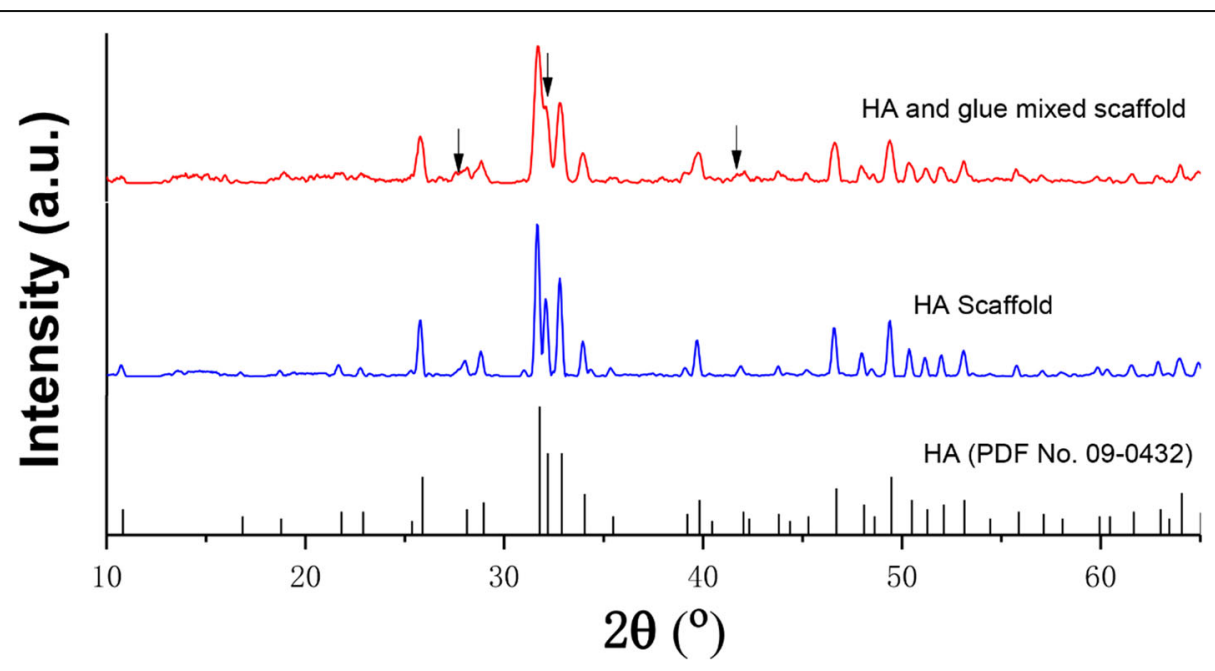

Fig. 3 XRD patterns of HA scaffolds before and after sintering. The black arrows represent the peaks of the glue 


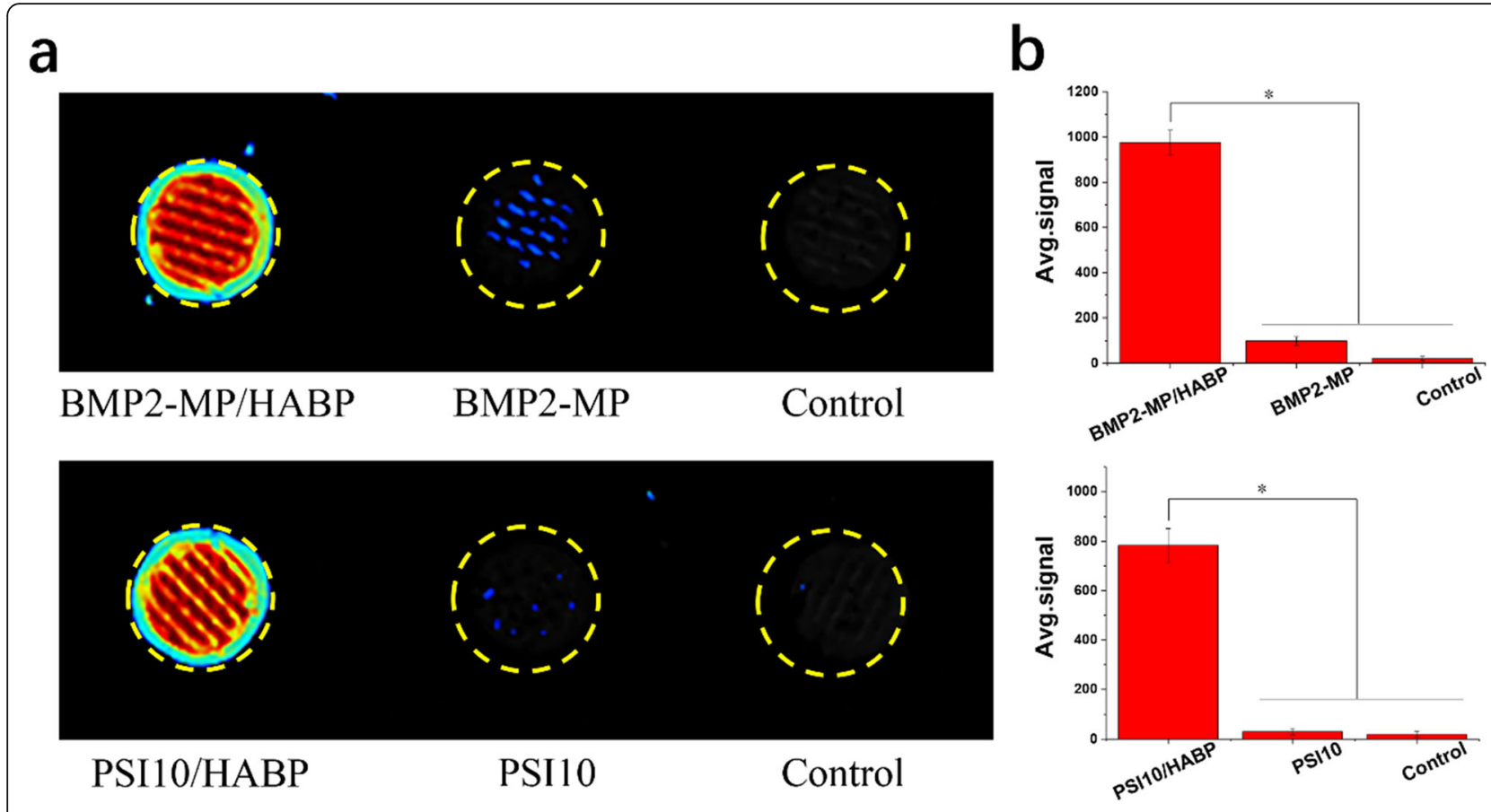

Fig. 4 a Fluorescent images of HA scaffold combined with BMP2-MP/HABP, BMP2-MP, PSI10/HABP, PSI10 and control. b Average signal intensity on different scaffold surfaces $\left(n=3,{ }^{*} p<0.05\right)$

polypeptides that were present. When the HABP tag was added to the BMP2-MP and PSI10 terminals, the binding capability to the HA scaffold was significantly enhanced compared with the no-tag polypeptides. As shown in Fig. 4b, the average signal intensities of BMP2MP/HABP and PSI10/HABP were 9.91 and 11.16 times higher than that of BMP2-MP and PSI10, respectively. The amount of BMP2-MP/HABP and BMP2-MP absorbed by the HA scaffolds were $398.41 \mathrm{ng}$ and 56.31ng, respectively (Fig. 5a). The amount of PSI10/ HABP and PSI10 absorbed by the HA scaffolds were 83.67 and $13.34 \mu \mathrm{g}$, respectively (Fig. $5 \mathrm{~b}$ ). As shown in Fig. $5 \mathrm{c}$ and $\mathrm{d}$, the polypeptides with HABP joint were released slowly, and the cumulative release rates of BMP2$\mathrm{MP} / \mathrm{HABP}$ and PSI10/HABP were 23.45 and $42.54 \%$ during the release period of $72 \mathrm{~h}$. Interestingly, the cumulative release rates of BMP2-MP and PSI10 were 95.76 and $94.11 \%$, respectively. The above results indicate that the HABP tag in the polypeptide can specifically bind with the HA material to enhance the loading capacity and slow release capability. SEM was used to observe and evaluate the changes in the surface morphology of HA scaffolds bound with different groups of peptides. As shown in Fig. 6, in the BMP2/HABP and PSI10/HABP groups, HA particles exhibited a rough surface and a large number of uniform polypeptides were deposited (size range: $10-30 \mathrm{~nm}$ ). In the BMP2MP and PSI10 groups, the surface of HA particles was relatively smooth and showed a small amount of polypeptide deposition. The above results also prove that the introduction of HABP tag enhanced the binding capability of polypeptide to the HA scaffold and the roughness of scaffold surface. In addition, as shown in Fig. S3, EDS experiments were used to scan the elements on the surface of different scaffolds, and the results showed that the scaffolds contained the HABP polypeptide displayed higher nitrogen content than other groups, which further proved the binding ability of HABP and HA.

The HABP polypeptide contains 12 amino acids that belong to a kind of solid-binding peptides (SBPs). SBPs are polypeptides with 7-12 amino acids. They are characterised by their capability to identify a certain kind of material and bind to its surface. SBPs act similar to a 'bridge' between biological active factors (peptides and growth factors) and materials (metals, inorganic materials and carbohydrates), endowing materials with effective biological functions. The most important function of SBPs is the increase in binding force between bioactive molecules and materials and realisation of their slow release [30].

\section{Antibacterial}

E. coli and S. aureus strains were used as model strains to evaluate the antibacterial capacity of scaffolds by calculating and observing the diameter of the antibacterial ring. Because E. coli belongs to the Gram-negative strain and $S$. aureus belongs to the Gram-positive strain, they are commonly used to evaluate antimicrobial capacity. 

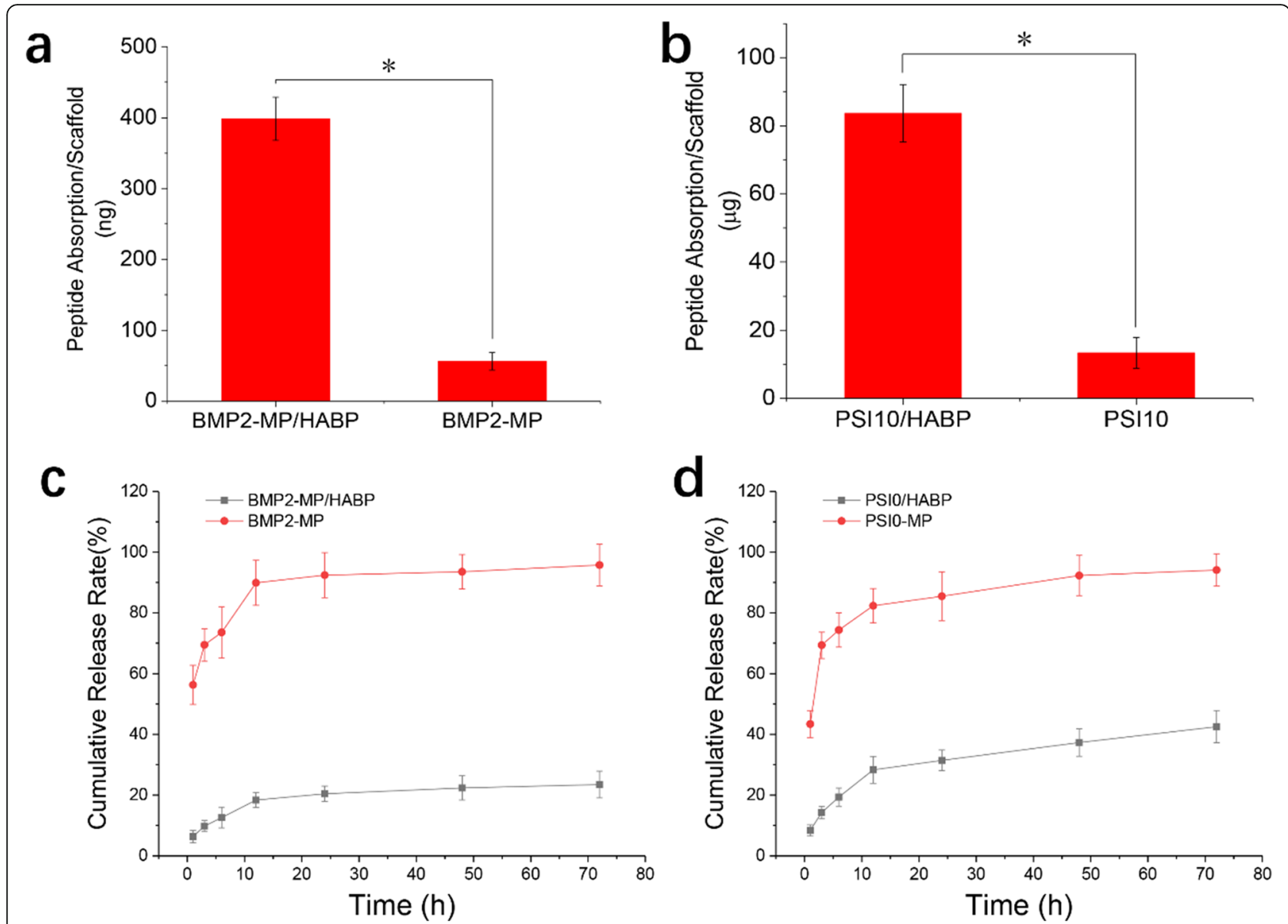

Fig. 5 The ability of 3D-printed HA scaffolds to absorb and release polypeptides. $\mathbf{a}$ and $\mathbf{c}$ BMP2-MP and BMP2-MP/HABP, b and $\mathbf{d}$ PSI10 and BMP10/HABP. $\left(n=3,{ }^{*} p<0.05\right)$
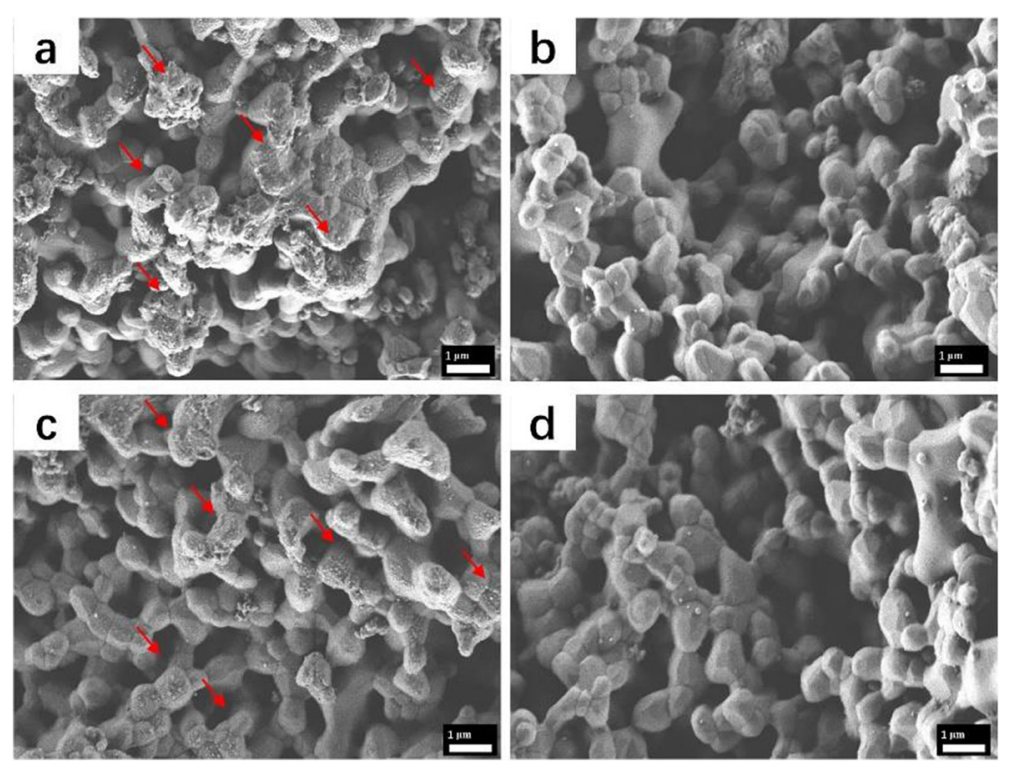

Fig. 6 Surface morphology of HA scaffolds bound with a BMP2-MP /HABP, b BMP2-MP, c PSI10/HABP and d PSI10, the red arrow indicates the polypeptide 
As shown in Fig. 7a, when the HABP tag was introduced into the PSI10 polypeptide terminal, the scaffold showed a significant antibacterial effect compared with the PSI10 group with E. coli and $S$. aureus. The bacterial inhibition zones of PSI10/HABP@HA and PSI10@HA scaffolds on $E$. coli plate were $14.47 \pm 0.89$ and $7.97 \pm$ $0.58 \mathrm{~mm}$, respectively. When the HABP tag was introduced, the bacterial inhibition zone of the scaffold bound to the HABP/PSI10 polypeptide was 1.82 times that of PSI10 polypeptide. In the $S$. aureus group, the bacterial inhibition zones of HABP/PSI10 and PSI10 scaffolds were $13.15 \pm 0.97$ and $7.12 \pm 0.48 \mathrm{~mm}$, respectively. The bacterial inhibition zone of HABP/PSI10@HA scaffold was 1.85 times that of PSI10 (Fig. 7b). Further experiments were carried out to demonstrate the antibacterial activity of the scaffolds by live and dead staining, see Fig. S4. The experimental results were consistent with the results of bacterial inhibition zone. The enhancement of antibacterial capability was mainly due to the specific binding capability of HABP and HA materials, which led to the firm binding of PSI10/HABP antimicrobial peptides on the surface of HA particles (Fig. 6).

An excellent bone defect repair scaffold should not only have good osteogenic induction capability but also the capability to control postoperative infection. In the preparation of bone repair scaffolds, the addition of antibacterial molecules is an effective method to prevent postoperative infection [31, 32]. Huan Sun et al. used calcium-phosphate and berberine to prepare 3D printing bio-inks and printed a bone repair scaffold with antibacterial capability. Berberine played an antibacterial role and as a kind of traditional chinese medicine, it can effectively inhibit gram-negative and gram-positive bacteria. In order to ensure the antibacterial activity of the scaffold, which had not been sintered; thus, the mechanical properties of the scaffold were poor and the porosity was low [33]. As shown in Fig. S5, the compression strength of HA scaffolds before and after sintering were $20.67 \pm 1.10 \mathrm{MPa}$ and $26.83 \pm 1.40 \mathrm{MPa}$, respectively. It can be seen from the above results that the compression strength of the scaffold increased by $29.8 \%$ after sintering. The scaffolds prepared in our study were sintered to obtain HA scaffolds with a suitable pore structure. Then, the antibacterial peptide PSI10 with HA-specific binding capability was used to bind to the scaffold surface to achieve a long-term antibacterial effect. This antibacterial strategy is suitable for inorganic 3D-printed bone repair scaffolds.

\section{Cytocompatibility of HA scaffold binding with PSI10/ HABP and BMP2-MP/HABP}

To evaluate the cytocompatibility of 3D-printed HA scaffolds combined with PSI10/HABP and BMP2-MP/ HABP, we stained Mc-3T3-E1 cells grown on different groups of scaffolds with calcein-AM and PI. In Fig. 8, the green fluorescent image indicates living cells growing on the scaffolds. The results show that all the scaffolds achieved good cell adhesion capability, a large number of cells grew on the scaffold surface and the morphology was intact. After the cells were stained with PI, the dead cells were almost invisible on the scaffold. The introduction of the HABP tag into the PSI10 and BMP2-MP terminals enhanced their capability to bind to the HA scaffold without affecting cell adhesion. CCK- 8 results showed no significant difference in cell proliferation

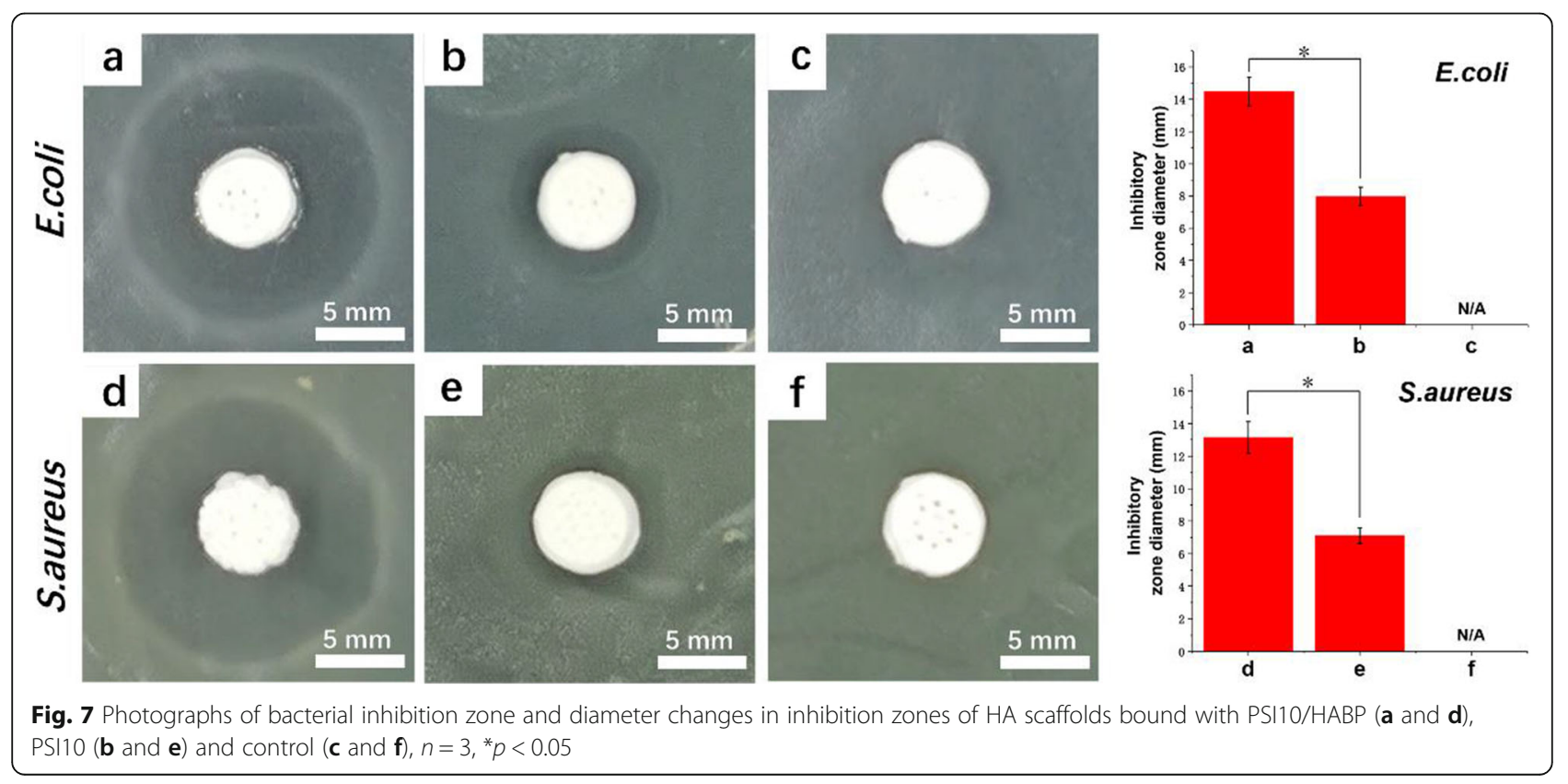



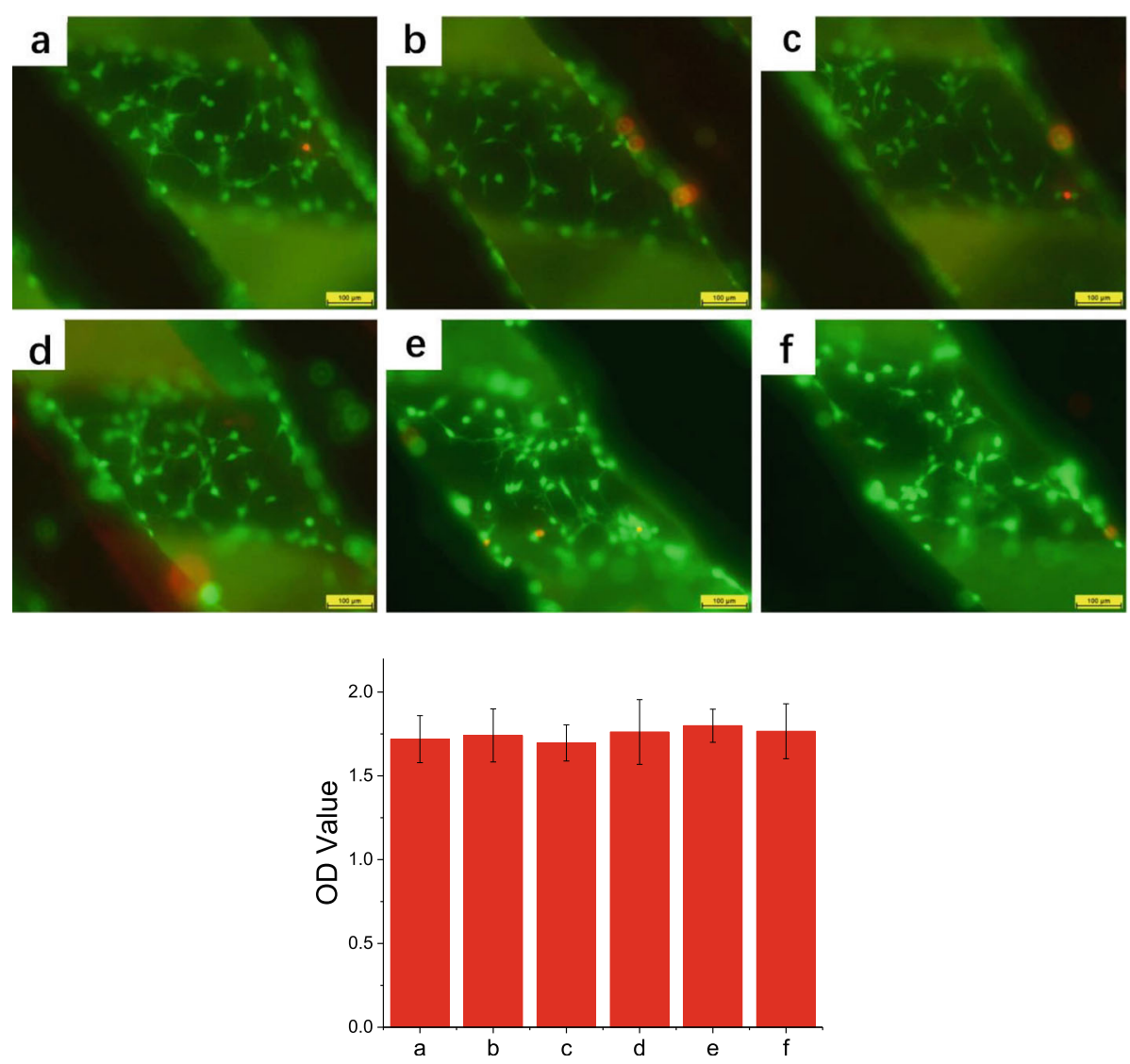

Fig. 8 Images of live and dead staining and CCK-8 assay of MC-3T3-E1 cells cultured on a HA, b PSI10@HA, c PSI10/HABP@HA, d BMP2-MP@HA, e BMP2-MP/HABP@HA and f PSI10/HABP\&BMP2-MP/HABP@HA scaffolds for 3 days. Bar =100 $\mu \mathrm{m}$
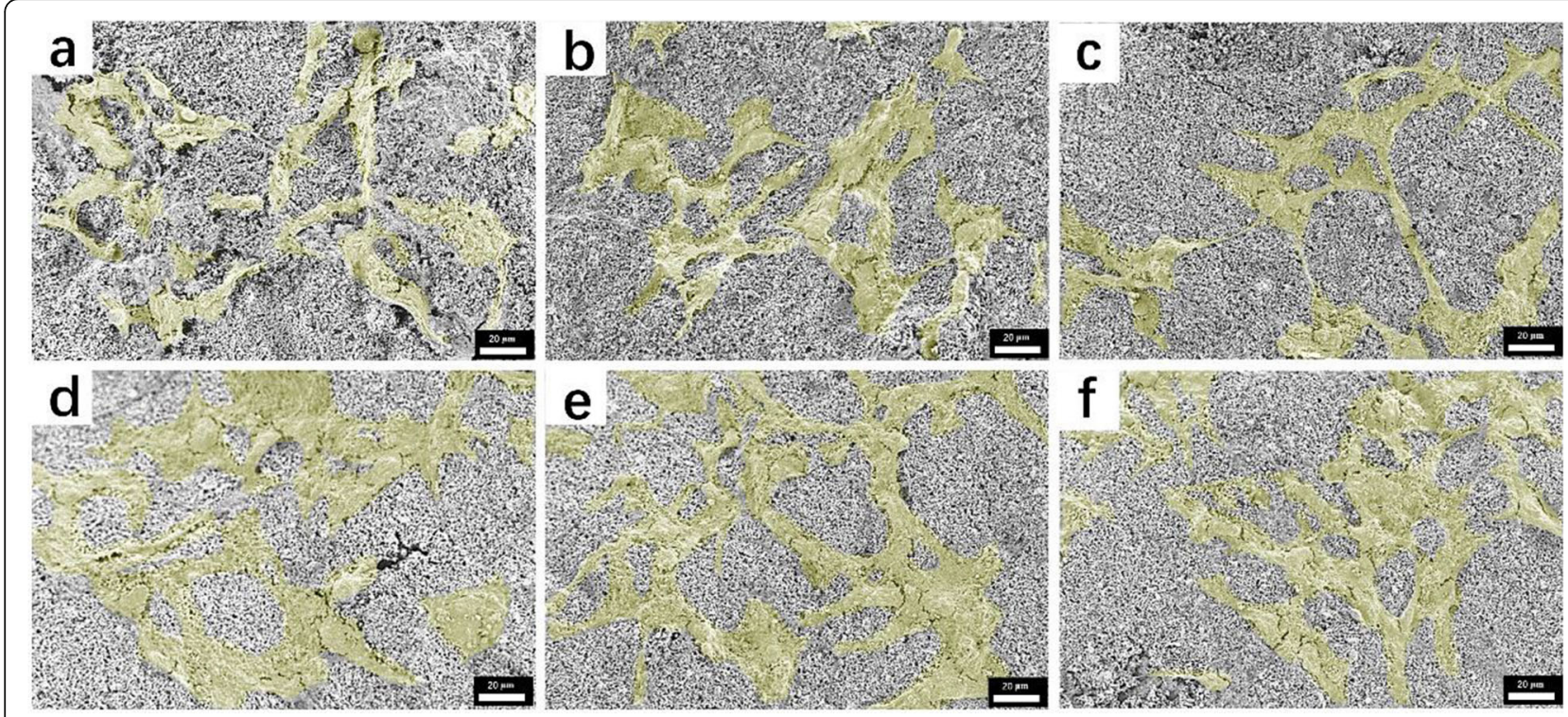

Fig. 9 SEM images of MC-3T3-E1 cells cultured for 3 days on different scaffolds (a HA, b PSI10@HA, c PSI10/HABP@HA, d BMP2-MP@HA, e BMP2MP/HABP@HA and $\mathbf{f}$ PSI10/HABP\&BMP2-MP/HABP@HA). (The yellow areas represent areas of cell adhesion, scale bar =20 $\mu \mathrm{m}$ ) 
among all groups, which was basically consistent with the results of cell adhesion. We used SEM to acquire images of growing cells on the scaffold to further observe their morphology. As shown in Fig. 9, a large number of cells grew on the surface of each scaffold and the extracellular matrix secreted by the cells tightly wrapped the scaffold filaments. The above results indicate that after surface modification, HA scaffolds would not affect cell adhesion and proliferation.

HA is an excellent bone repair material and similar to bioapatite in natural bone in terms of composition and crystallography [34]. HA dissolves slightly in the body, releases calcium ions, participates in body metabolism, has a stimulating or inducing effect on bone hyperplasia, promotes the repair of defect tissue and shows biological activity. Our cell adhesion results reveal the excellent cell adhesion capability of the 3D-printed HA scaffold. A complete and full cell morphology was observed on the HA scaffold, whereas the scaffold surface was covered with considerable amount of extracellular matrix. After the scaffolds were coated with PSI10 and BMP2-MP, no significant negative effects were observed on the cell adhesion of scaffolds, which indicates that the PSI10 and BMP2-MP bound on the scaffold surface were noncytotoxic to the cells.

\section{Effect of BMP2-MP/HABP and BMP2-MP on the expressions of osteogenic differentiation-related marker genes and proteins}

To evaluate the effect of osteogenic differentiation of BMP2-MP/HABP and BMP2-MP, we used $q \mathrm{PCR}$ to detect the osteogenic differentiation-related marker genes and proteins (Runx2, COL-I and OCN). As shown in Fig. 10, the mRNA expression levels of Runx2, COL-I and OCN in BMP2-MP/HABP and BMP2-MP groups were significantly higher than those in HA, PSI10 and PSI10/HABP groups $(p<0.05)$. The expression levels of Runx2 in the BMP2-MP/HABP and PSI10/ HABP\&BMP2-MP/HABP groups were 6.78 and 6.42 times higher than those in the HA group, respectively. The expression level of COL-I in BMP2-MP/HABP and
PSI10/HABP\&BMP2-MP/HABP groups were 3.64 and 3.36 times that of HA group, respectively. The OCN expression levels in BMP2-MP/HABP and PSI10/ HABP\&BMP2-MP/HABP groups were 12.67 and 11.56 times that in the HA group, respectively. The expression levels of Runx2, COL-I and OCN in the BMP2-MP group were slightly higher than those of the HA group. The expression levels of Runx2, COL-I and OCN in the PSI10 and PSI10/HABP groups showed no significant difference from those of the HA group. Runx-2, OCN and COL-I protein expressions were also detected with Western blot on day 7 (Fig. 11). The Western blot results indicated that BMP2-MP/HABP and PSI10/ HABP\&BMP2-MP/HABP were more favourable of the protein expressions of Runx, COL-I and OCN than the others.

Runx2 is a transcription factor that induces immature osteocytes to differentiate into mature ones. In groups BMP2-MP/HABP and PSI10/HABP\&BMP2-MP/HABP, BMP2-MP were stably bound to the surface of HA scaffolds; BMP2-MP activated the intracellular signal transduction pathways by binding to BMP receptors on the extracellular surface [22]. Firstly, the expression level of Runx2 was regulated. Subsequently, the up-regulated expression of Runx2 stimulated osteogenic differentiation of the cells via the up-regulated expression of COL-I and $\mathrm{OCN}$. Western blot results also confirmed the role of BMP2-MP/HABP and PSI10/HABP\&BMP2-MP/ HABP in promoting osteogenic differentiation of cells. This strong osteogenic effect bound with BMP2-MP/ HABP can be attributed to the contribution of HABP.

\section{Osteogenesis differentiation}

The level of ALP expression is an important marker of cell osteogenic differentiation. We used ALP staining to detect and evaluate the osteoinduction capability of scaffolds bound with BMP2-MP/HABP. As shown in Fig. 12, the cells cultured on the BMP2-MP@HA group had a small number of purple-dyed cells. However, large numbers of cells were dyed purple in BMP2-MP/HABP@HA and PSI10/HABP\&BMP2-MP/HABP@HA scaffolds. No
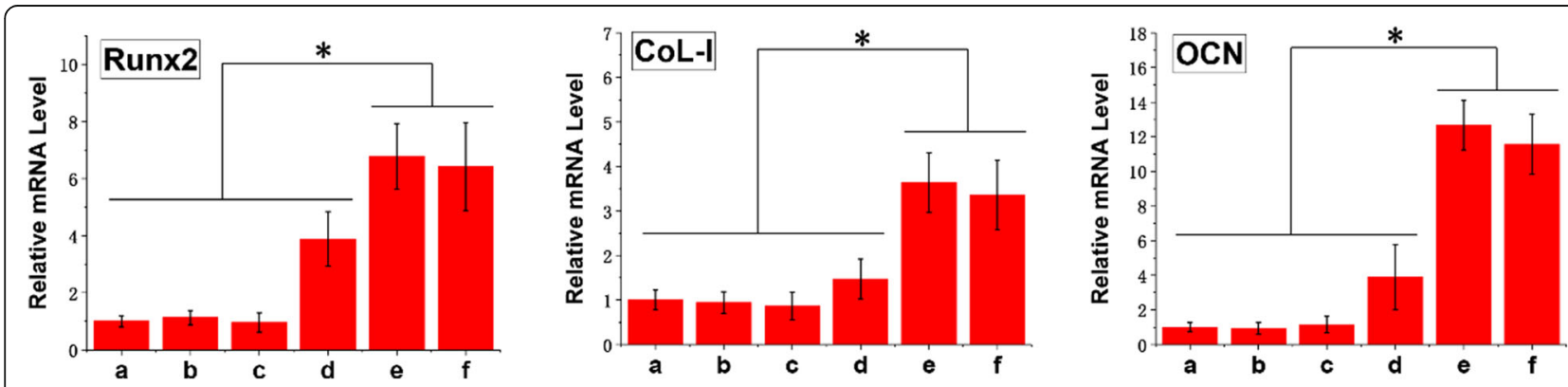

Fig. 10 Quantitative expression of Runx2, COL-I and OCN mRNAs by qPCR for 3 days. a HA, b PSI10@HA, c PSI10/HABP@HA, d BMP2-MP@HA, e BMP2-MP/HABP@HA and f PSI10/HABP\&BMP2-MP/HABP@HA $\left(n=3,{ }^{*} p<0.05\right)$ 


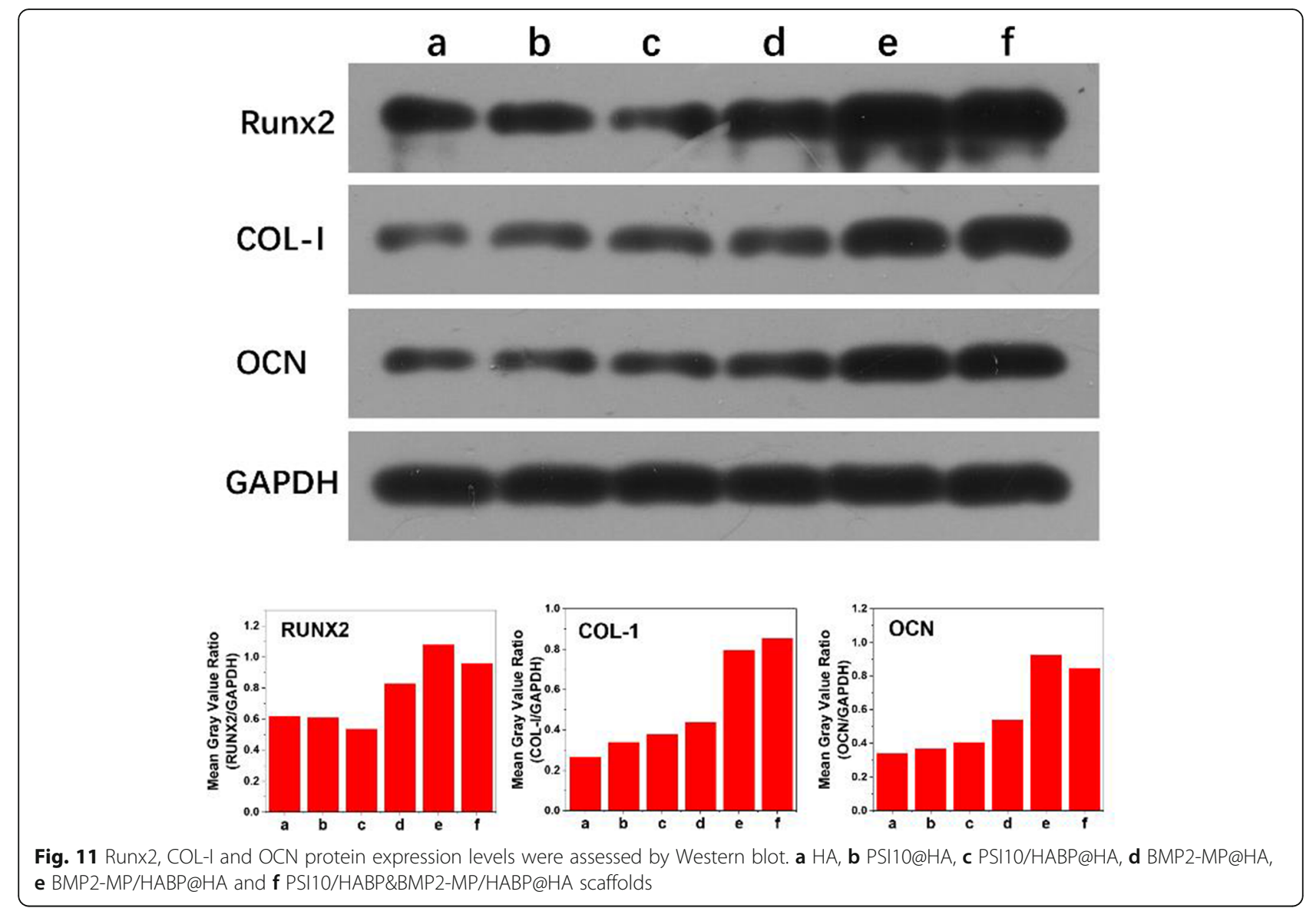

cell showed evident purple staining in the HA, PSI10@HA and PSI10/HABP@HA groups. We used pNPP method to detect the ALP expression level in cells. The ALP levels of BMP2-MP/HABP@HA and PSI10/HABP\&BMP2-MP/HABP@HA were 4.12 and 4.32 times that of $\mathrm{HA}$, respectively.
The above results indicate that the HA scaffold combined with a large number of BMP2-MP/HABP peptides resulted in osteogenic differentiation of cells, whereas PSI10 peptides had no evident effect on osteogenic differentiation. These results were consistent with gene expression and protein levels (Figs. 10 and 11,
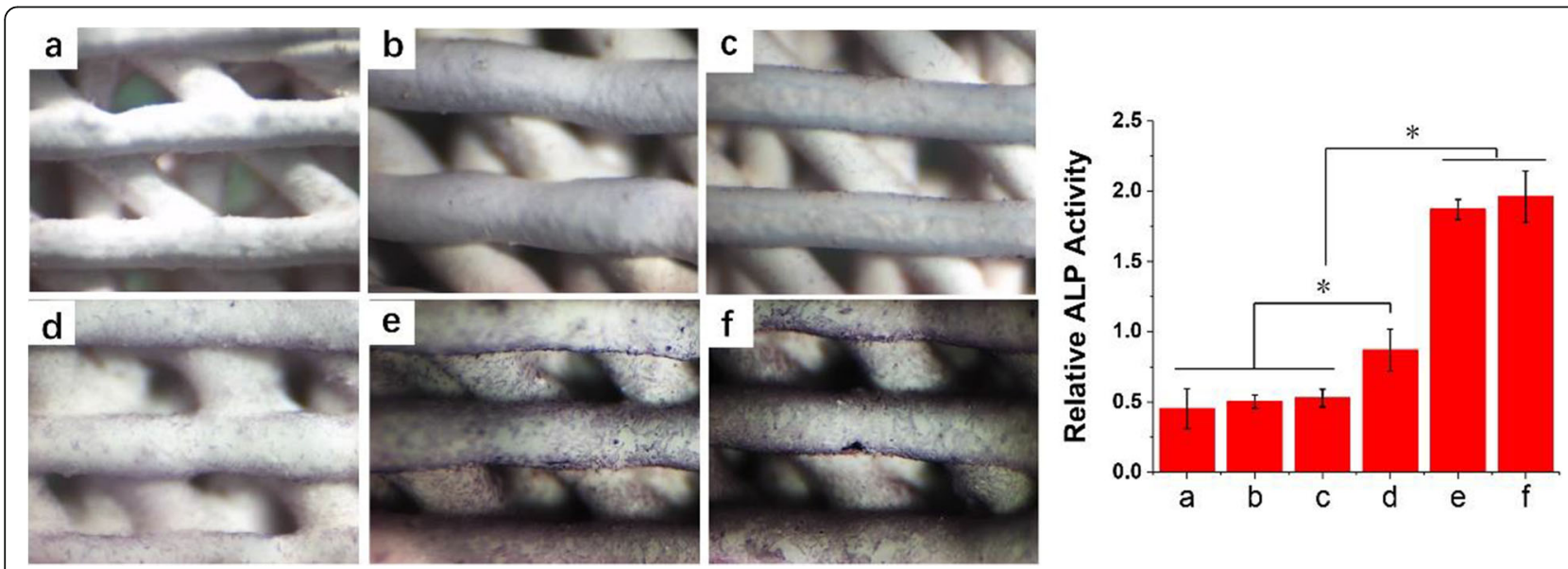

Fig. 12 ALP staining images of MC3T3-E1 cultured for 7 days on different scaffolds. a HA, b PSI10@HA, c PSI10/HABP@HA, d BMP2-MP@HA, e BMP2-MP/HABP@HA and f PSI10/HABP\&BMP2-MP/HABP@HA $\left(n=3,{ }^{*} p<0.05\right)$ 
respectively). ALP is a marker of early osteogenesis. When the activity of ALP is enhanced, it can promote the mineralisation of bone matrix. The above results also further demonstrate that when the end of BMP2-MP was added with HABP, the osteogenic effect of HA scaffold was significantly enhanced.

\section{Conclusions}

In this study, HABP, which can specifically bind to HA materials, was introduced into the C-terminal of BMP2MP and antimicrobial peptide PSI10. Given the strong binding capacity of HABP with HA, the HA material can stably load the BMP2-MP and PSI10. We used 3D printing technology to prepare HA scaffolds with controllable shape and porosity. When BMP2-MP/HABP and PSI10/ HABP polypeptides were specifically bound to HA scaffolds, the antibacterial and osteogenic induction of scaffolds were significantly enhanced. The 3D size of bone defect can be reconstructed based on CT data and a personalised scaffold with antibacterial and osteogenic induction capability can be prepared using 3D printing technology. In future experimental study, we will evaluate the bone repair ability of these scaffolds in vivo, and in vitro evaluate the osteogenic induction ability of these scaffolds on mesenchymal stem cells and the antibacterial ability of the scaffold against other types of bacteria.

\section{Abbreviations}

3D: Three-dimensional; HA: Hydroxyapatite; HABD: HA binding domain; BMP2: Bone morphogenetic protein 2; BMP2-MP: BMP2 mimetic peptide; PCL: Polycarbonate; DOPA: 3,4-dihydroxyphenylalanine; IGF1: Insulin-like growth factor 1; FITC: Fluorescein isothiocyanate; Micro-CT: Micro-computed tomography; SEM: Scanning electron microscopy; XRD: X-ray diffraction; S. aureus: Staphylococcus aureus; E. coli: Escherichia coli BL21; CCK-8: Cell Counting Kit-8; PI: Propidium iodide; GAPDH: Glyceraldehyde-3-phosphate dehydrogenase; COL-I: Type 1 collagen; OCN: Osteocalcin;

PVDF: Polyvinylidene fluoride; SD: Standard deviation; pNPP: p-Nitrophenyl Phosphate; SBPs: Solid-binding peptides

\section{Supplementary Information}

The online version contains supplementary material available at https://doi. org/10.1186/s13036-021-00273-6.

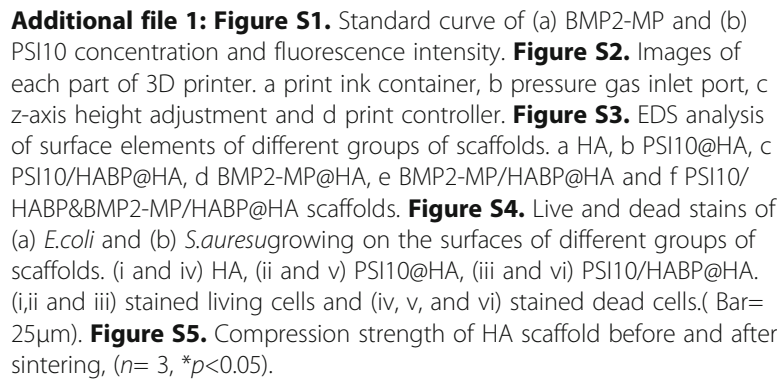

\section{Authors' contributions}

Li Jinlong, Cao Jian and Zhang Limin designed and conceived this study, Liu Zhongxing and Wu Shaohong carried out the experimental work and wrote the manuscript, Wang Yuanzheng carried out the 3D printing of the scaffold, In vitro cell experiments were conducted by Haipeng Gao. The author(s) read and approved the final manuscript.

\section{Funding}

This research was supported by Inner Mongolia Grassland Talent Project Youth Innovation Talent Training Program (2016348) and Inner Mongolia Medical University Million Project Joint project (YKD2016KJBW(LH)035).

Availability of data and materials

Not applicable.

\section{Declarations}

Ethics approval and consent to participate

Not applicable.

\section{Consent for publication}

Not applicable.

\section{Competing interests}

The authors declare that they have no competing interests.

\section{Author details}

${ }^{1}$ Department of Orthopedics, Affiliated Hospital of Chifeng University, Inner Mongolia 024000 Chifeng, People's Republic of China. ${ }^{2}$ Department of Stomatology, Affiliated Hospital of Chifeng University, Inner Mongolia 024000 Chifeng, People's Republic of China. ${ }^{3}$ Department of Ophthalmology, Affiliated Hospital of Chifeng University, Inner Mongolia 024000 Chifeng, People's Republic of China.

Received: 27 May 2021 Accepted: 17 July 2021

Published online: 09 August 2021

\section{References}

1. Nguyen TDT, Jang YS, Kim YK, Kim SY, Lee MH, Bae TS. OsteogenesisRelated Gene Expression and Guided Bone Regeneration of a StrontiumDoped Calcium-Phosphate-Coated Titanium Mesh. Acs Biomater Sci Eng. 2019;5(12):6715-24.

2. Pare A, Charbonnier B, Tournier P, Vignes C, Veziers J, Lesoeur J, Laure B, Bertin H, De Pinieux G, Cherrier G, et al. Tailored Three-Dimensionally Printed Triply Periodic Calcium Phosphate Implants: A Preclinical Study for Craniofacial Bone Repair. Acs Biomater Sci Eng. 2020;6(1):553-63.

3. Nair LS, Laurencin CT. Biodegradable polymers as biomaterials. Prog Polym Sci. 2007:32(8-9):762-98.

4. Sen MK, Miclau T. Autologous iliac crest bone graft: Should it still be the gold standard for treating nonunions? Injury. 2007;38:75-80.

5. Honeybul S, Morrison DA, Ho KM, Lind CRP, Geelhoed E. A randomized controlled trial comparing autologous cranioplasty with custom-made titanium cranioplasty. J Neurosurg. 2017;126(1):81-90.

6. Szostakowski B, DeMaio M. Ideal xenograft or a perfect bone substitute?-A retrospective review and analysis of the historical concept of ivory implants in orthopaedics. Int Orthop. 2020;44(5):1003-9.

7. Liu DH, Nie W, Li DJ, Wang WZ, Zheng LX, Zhang JT, Zhang JL, Peng C, Mo XM, He CL. 3D printed PCL/SrHA scaffold for enhanced bone regeneration. Chem Eng J. 2019:362:269-79.

8. Chen L, Shao LP, Wang FP, Huang YF, Gao FH. Enhancement in sustained release of antimicrobial peptide and BMP-2 from degradable three dimensional-printed PLGA scaffold for bone regeneration. Rsc Advances. 2019;9(19):10494-507.

9. Li XY, Wang Y, Guo M, Wang ZL, Shao NN, Zhang PB, Chen XS, Huang YB. Degradable Three Dimensional-Printed Polylactic Acid Scaffold with LongTerm Antibacterial Activity. Acs Sustainable Chemistry Engineering. 2018; 6(2):2047-54.

10. Li XJ, Yuan Y, Liu LY, Leung YES, Chen YY, Guo YX, Chai Y, Chen Y. 3D printing of hydroxyapatite/tricalcium phosphate scaffold with hierarchical porous structure for bone regeneration. Bio-Design Manufacturing. 2020; 3(1):15-29. 
11. Xie ZJ, Yan DY, Zhou Q, Wu ZY, Weng SJ, Boodhun V, Bai BL, Shen ZJ, Tang $\mathrm{JH}$, Chen $\mathrm{L}$, et al. The fast degradation of beta-TCP ceramics facilitates healing of bone defects by the combination of BMP-2 and Teriparatide. Biomed Pharmacother. 2019;112:10.

12. Ke D, Tarafder S, Vahabzadeh S, Bose S. Effects of $\mathrm{MgO}, \mathrm{ZnO}, \mathrm{SrO}$, and $\mathrm{SiO} 2$ in tricalcium phosphate scaffolds on in vitro gene expression and in vivo osteogenesis. Mater Sci Eng C Mater Biol Appl. 2019;96:10-9.

13. He X, Liu Y, Tan Y, Grover LM, Song J, Duan S, Zhao D, Tan X. Rubidiumcontaining mesoporous bioactive glass scaffolds support angiogenesis, osteogenesis and antibacterial activity. Mater Sci Eng C Mater Biol Appl. 2019;105:110155

14. Campana V, Milano G, Pagano E, Barba M, Cicione C, Salonna G, Lattanzi W, Logroscino G. Bone substitutes in orthopaedic surgery: from basic science to clinical practice. J Mater Sci Mater Med. 2014;25(10):2445-61.

15. Wei D, Qiao R, Dao J, Su J, Jiang C, Wang X, Gao M, Zhong J. Soybean Lecithin-Mediated Nanoporous PLGA Microspheres with Highly Entrapped and Controlled Released BMP-2 as a Stem Cell Platform. Small. 2018;14(22): e1800063.

16. Rahman M, Peng X-L, Zhao X-H, Gong H-L, Sun X-D, Wu Q, Wei D-X. 3D bioactive cell-free-scaffolds for in-vitro/in-vivo capture and directed osteoinduction of stem cells for bone tissue regeneration. Bioact Mater. 2021;6(11):4083-95.

17. Gadalla D, Goldstein AS. Improving the Osteogenicity of PCL Fiber Substrates by Surface-Immobilization of Bone Morphogenic Protein-2. Ann Biomed Eng. 2020;48(3):1006-15.

18. Zhang Q, He QF, Zhang TH, Yu XL, Liu Q, Deng FL. Improvement in the delivery system of bone morphogenetic protein-2: a new approach to promote bone formation. Biomed Mater. 2012;7(4):11.

19. Chen B, Lin H, Zhao Y, Wang B, Zhao Y, Liu Y, Liu Z, Dai J. Activation of demineralized bone matrix by genetically engineered human bone morphogenetic protein-2 with a collagen binding domain derived from von Willebrand factor propolypeptide. J Biomed Mater Res Part A. 2007; 80A(2):428-34

20. Zhang C, Miyatake $H$, Wang $Y$, Inaba T, Wang Y, Zhang P, Ito Y. A Bioorthogonal Approach for the Preparation of a Titanium-Binding Insulinlike Growth-Factor-1 Derivative by Using Tyrosinase. Angew Chem Int Ed. 2016;55(38):11447-51.

21. Roy MD, Stanley SK, Amis EJ, Becker ML. Identification of a highly specific hydroxyapatite-binding peptide using phage display. Adv Mater. 2008; 20(10):1830-+

22. Zouani OF, Chollet C, Guillotin B, Durrieu M-C. Differentiation of preosteoblast cells on poly(ethylene terephthalate) grafted with RGD and/or BMPs mimetic peptides. Biomaterials. 2010;31(32):8245-53.

23. Yang S-T, Shin SY, Hahm K-S, Kim Jl. Design of perfectly symmetric Trp-rich peptides with potent and broad-spectrum antimicrobial activities. Int J Antimicrob Agents. 2006;27(4):325-30.

24. LU XQ, Lu JH, Zhang L, XU YJ. Effect of ANGPTL7 on Proliferation and Differentiation of MC3T3-E1 Cells. Med Sci Monit. 2019;25:9524-30.

25. Huang D, Hou X, Zhang D, Zhang Q, Yan C. Two novel polysaccharides from rhizomes of Cibotium barometz promote bone formation via activating the BMP2/SMAD1 signaling pathway in MC3T3-E1 cells. Carbohydr Polym. 2020;231:115732.

26. Chen L, Deng C, Li J, Yao Q, Chang J, Wang L, Wu C. 3D printing of a lithium-calcium-silicate crystal bioscaffold with dual bioactivities for osteochondral interface reconstruction. Biomaterials. 2019;196:138-50.

27. Dang W, Ma B, Li B, Huan Z, Ma N, Zhu H, Chang J, Xiao Y, Wu C. 3D printing of metal-organic framework nanosheets-structured scaffolds with tumor therapy and bone construction. Biofabrication. 2020;12(2):025005.

28. Tsuruga E, Takita H, Itoh H, Wakisaka Y, Kuboki Y. Pore size of porous hydroxyapatite as the cell-substratum controls BMP-induced osteogenesis. J Biochem. 1997;121(2):317-24.

29. Diao JJ, Ding HW, Huang MQ, Fu XL, Zou F, Li TJ, Zhao NR, Mao CB, Wang YJ. Bone Defect Model Dependent Optimal Pore Sizes of 3D-Plotted BetaTricalcium Phosphate Scaffolds for Bone Regeneration. Small Methods. 2019; 3(11):11.

30. Bansal R, Care A, Lord MS, Walsh TR, Sunna A. Experimental and theoretical tools to elucidate the binding mechanisms of solid-binding peptides. New Biotechnol. 2019:52:9-18.

31. Lin M-C, Chen C-C, Wu IT, Ding S-J. Enhanced antibacterial activity of calcium silicate-based hybrid cements for bone repair. Mater Sci Eng C Mater Biol Appl. 2020;110:110727.
32. Wang DY, Liu Y, Liu YL, Yan L, Zaat SAJ, Wismeijer D, Pathak JL, Wu G. A dual functional bone-defect-filling material with sequential antibacterial and osteoinductive properties for infected bone defect repair. J Biomed Mater Res A. 2019:107(10):2360-70.

33. Sun H, Hu C, Zhou CC, Wu LN, Sun JX, Zhou XD, Xing F, Long C, Kong QQ, Liang J, et al. 3D printing of calcium phosphate scaffolds with controlled release o antibacterial functions for jaw bone repair. Mater Design. 2020;189: 13.

34. Kumar A, Kargozar S, Baino F, Han SS. Additive Manufacturing Methods for Producing Hydroxyapatite and Hydroxyapatite-Based Composite Scaffolds: A Review. Front Mater. 2019:6:20.

\section{Publisher's Note}

Springer Nature remains neutral with regard to jurisdictional claims in published maps and institutional affiliations.
Ready to submit your research? Choose BMC and benefit from:

- fast, convenient online submission

- thorough peer review by experienced researchers in your field

- rapid publication on acceptance

- support for research data, including large and complex data types

- gold Open Access which fosters wider collaboration and increased citations

- maximum visibility for your research: over $100 \mathrm{M}$ website views per year

At BMC, research is always in progress.

Learn more biomedcentral.com/submissions 